\author{
Journal of Al-Azhar University Engineering Sector
}

Vol.15, No. 54, January, 2020, 92-99

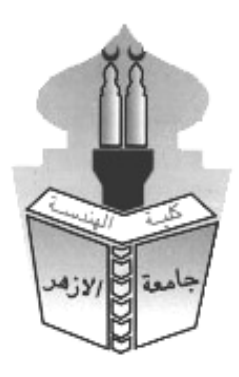

\title{
INVESTIGATION STUDY FOR DIFFERENT PARAMETERS AFFECTING THE COLD ROLLING PROCESS OF FLAT ALUMINUM PLATES
}

\author{
Fathy Nagyed, Ali Nasser and Mazen Negm \\ Mechanical Engineering Department, Faculty of Engineering, Al-Azhar University, Cairo, \\ Egypt \\ *Corresponding Author Email: fathyelsgendy85@azhar.edu.eg
}

ABSTRACT

Metal rolling processes are usually subjected to continuous development for increasing the efficiency of metals industry and broadening the applicability of soft metals in the structural applications. During this study, cold plate rolling have been conducted under different conditions. Particularly, the rolling power and the resulted separating force have been analyzed after changing the roll diameter, the draft thickness, and the lubricant type. It was observed that, decreasing the reduction by pass and reducing the roll diameter could minimize the need for high power during operation. It was also noticed that, among the different experiments, using olive and paraffin oil as lubricant at the roll-metal surface show a significant effect on reducing the power consumption and increasing the rolling process efficiency in a high agreement with the mathematical modeling.

KEY WORDS: Cold rolling, Power analysis, Draft thickness, Roll diameter, Lubricants.

$$
\begin{aligned}
& \text { دراسة العوامل المختلفة الموثره إثناء الارفلة علي البارد للالومنيوم }
\end{aligned}
$$

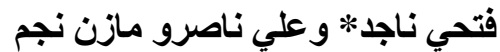

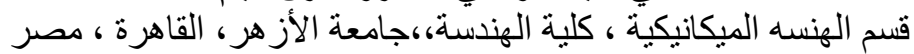

Email: fathyelgendy85@azhar.edu.eg: البريد الاليكتروني للباحث الرئيسئ، كلية،

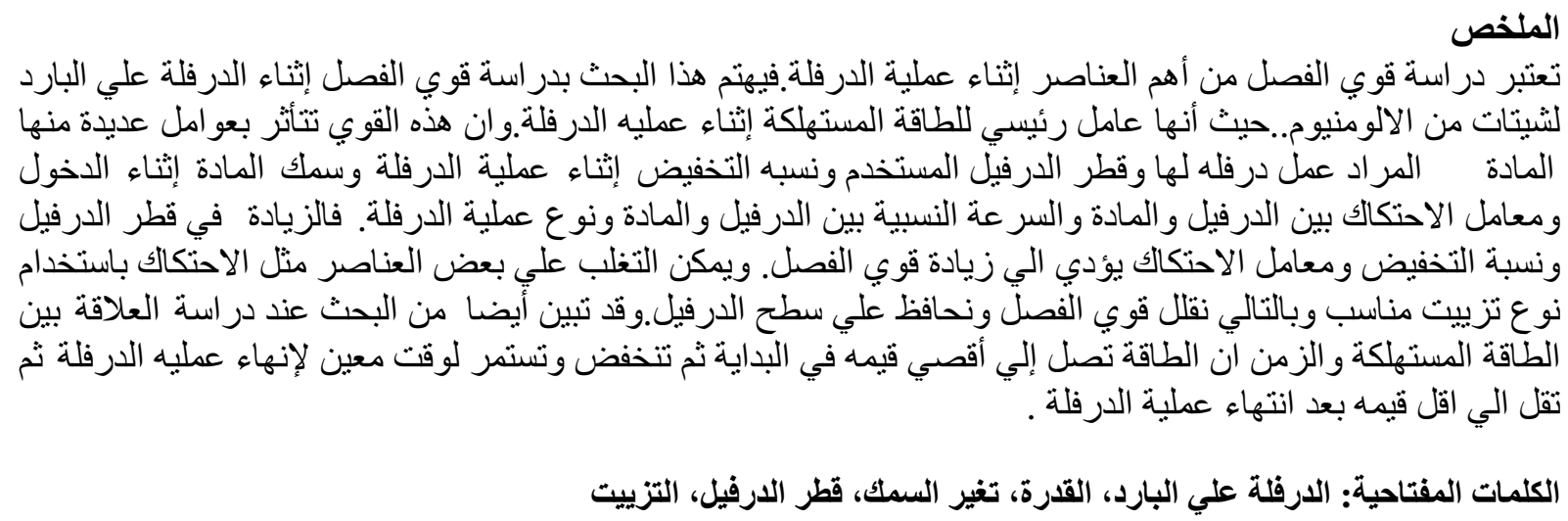

\section{INTRODUCTION}

Rolling is one of the oldest processes of metal forming industry. It's certainly importance is proved by the tremendous annually volume and the wide variety of rolled products. Rolling process in general and the plate rolling in particular has attracted many research efforts to reduce the thickness of the work piece to the pre-determined thickness, effectively. During plate rolling, two work-rolls, are rotating in opposite directions to draw the plate into the roll 
gap and force it to the exit, causing the required thickness reduction, as illustrated schematically in Figure 1 [1-5].

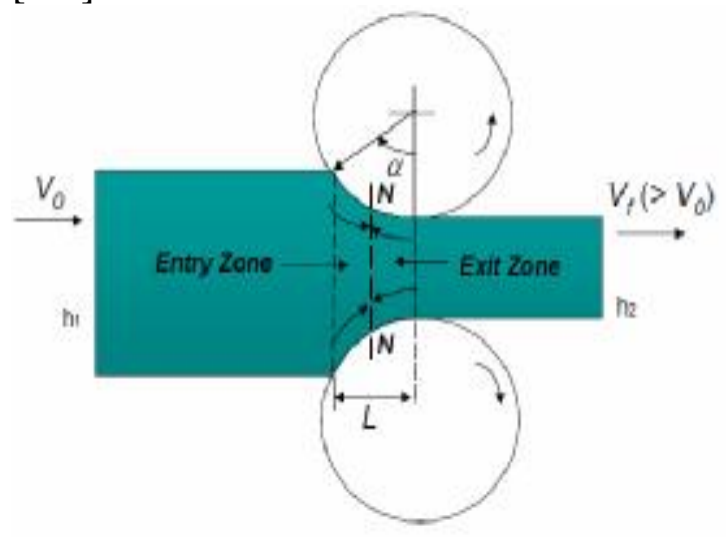

Figure 1. Schematic Illustration of The Plate Rolling Process

Roll separating force is considered the main governing parameter during the plate rolling process. The magnitude of this force is affected by the material being rolled, the diameter of the rolls and the rate at which the material being compressed [1]. As per the literature, Increasing roll diameter does increase the roll separating force, therefore power consumed during rolling increase [2]. The increase of reduction ratio during the rolling process, also increase roll separating force. The change in friction lead to the change in roll force $[1,2]$.

The development of roll qualities and roll-making technology has a direct reflect on the development of rolling technology, and rolled products dimensional and surface quality. The force arising during rolling are transferred by the roll neck bearings, to the adjusting screw and roll housing. This force depends on the following factors:

(a) The projected area of contact between roll and stock.

(b) The resistance to deformation of the rolled stock which is generally assumed to be a constant mean value along the projected arc of contact.

(c) The roll diameter (the increase in roll diameter lead to the increase in roll separating force) [1-15].

Studying the rolling process by finite element models have imported great attention from researchers since 1980. Using these finite element models, the governing differential equations, which describe the three-dimensional deformation behavior of the work piece, can be solved. The finite element method provide more accurate information compared to the simplified analytic methods $[14,15]$.

Several attempts has been reported to measure the pressure distribution between the rolls and work piece during rolling. Siebel et. al [2] used a large $(2 \times 2 \mathrm{~mm})$ pressure pin to measure the pressure distribution quantity. Siebel proposed a homogeneous deformation method requires the selection of an element in the workpiece and identifying all normal and frictional forces acting on this element. Siebel principal assumption was that the deformation of metal is homogenous throughout the whole deformation zone [3,4]. The homogenous deformation method doesn't take into account the revers direction of shear stresses since the effect of frictional forces is included as a scalar correction factor. Von Karman proposed a one-dimensional model for the rolling process, in which he neglected the spread in width. The ordinary differential equation describing the pressure distribution was established from a consideration of the equilibrium of forces acting on the elemental slab in the deformation zone [7 $10]$.

Orowan's model [8], [9] is considered to be the most comprehensive model, therefor, he used graphical integration techniques to solve Von Karman's equation. Thereafter, Sims [10] modified Orowan's model by using simplifying assumptions in order to obtain a closed form solution of the equilibrium equation. More recently, Alexander [11], [12] has introduced additional simplifications to Von Karman equation by presenting a computer-aided solution 
and obtained more accurate simulation results compared to previously reported homogeneous theories.

This study has been undertaken to decrease the power consumption and the separating force of plate rolling process of aluminum plates through different attempts mathematically and experimentally. Effects of rolls diameter, plate reduction ratio "draft", and lubricant type are considered during the aluminum plate rolling process using different mathematical models from literature. Thereafter, modelling results has been verified experimentally using a handmade rolling machine.

\section{MATHEMATICAL MODELING}

Different mathematical model has been applied during this study to investigate the effect of rolling parameters, specifically, plate thicknesses before and after rolling, and rolls diameter in the rolling power and the separating force. First, Ekelund's method [7]:

The formula derived by Ekelund's is:

$$
\mathrm{F}=b_{m} k \sqrt{R\left(h_{1}-h_{2}\right)}\left[1+\frac{1.6 \mu \sqrt{R\left(h_{1}-h_{2}\right)}-1.2\left(h_{1}-h_{2}\right)}{h_{1}+h_{2}}\right]
$$

Where:

F: roll separating force.

$\mathrm{R}$ : roll radius $(\mathrm{mm})$

$\Delta h:$ Reduction in thickness $\left(\mathrm{h}_{1}-\mathrm{h}_{2}\right)(\mathrm{mm})$.

$\mathrm{K}$ : yield stress of the rolled material $\left(\mathrm{N} / \mathrm{mm}^{2}\right)$

$\mu$ : Coefficient of friction

Secondly, Tselikas's Method, the roll force formula derived by Tselikov is [16];

$$
F=f_{d} \frac{k\left(2-\varepsilon_{h}\right)}{\varepsilon_{h} \sigma}\left[\left(\frac{1}{1-\varepsilon_{h}}\right)^{\sigma / 2}-1\right]
$$

Where:

$f_{d}: \quad=\mathrm{b}_{m} \mathrm{~L}_{d}$ the projected area of contact $\left(\mathrm{mm}^{2}\right)$

$\mathrm{b}_{m}=\frac{b_{1}+b_{2}}{2}$ (main width of the rolled stock mm), and $\mathrm{L}_{d}=\sqrt{R \Delta h}$ (Length of deformation zone $\mathrm{mm}$ ) where, $\mathrm{R}$ is the roll radius ( $\mathrm{mm})$, and $\Delta h=\mathrm{h}_{1}-\mathrm{h}_{2} \quad$ (height change in $\mathrm{mm}$ ).

$\mathrm{K}$ : yield stress of the rolled material $\left(\mathrm{N} / \mathrm{mm}^{2}\right)$

$\varepsilon_{h}=\frac{\Delta h}{h_{1}} \quad$ (Relative draught), $\sigma=\mu \sqrt{2 D / \Delta h}$ where $\mathrm{D}$ is the roll diameter $(\mathrm{mm})$, and $\mu$ is the coefficient of friction.

Finally, Siebel's method was implemented where the formula derived by Siebel for calculating the rolling separating force is in the form[17];

$$
\mathrm{F}=\mathrm{K} f_{d}
$$

Taking in consideration, only, the projected area of contact $\left(f_{e}\right)$ and the yield stress of the rolled material $(\mathrm{K})$ for calculating the rolling separating force $(\mathrm{F})$. 


\section{EXPERIMENTAL WORK}

First of all, the manufactured rolling machine which made by authors to be used in the present work is shown in Fig. 2. The dimensions of the working rolls and other specifications of the rolling machine are as following;

- Diameter of rollers $120 \mathrm{~mm}$ with a deformation zone of $250 \mathrm{~mm}$.

- Motor power $(3 \mathrm{~kW})$ with $1420 \mathrm{rpm}$.

- Rolling speed after gear box reduction is $33 \mathrm{rpm}$.

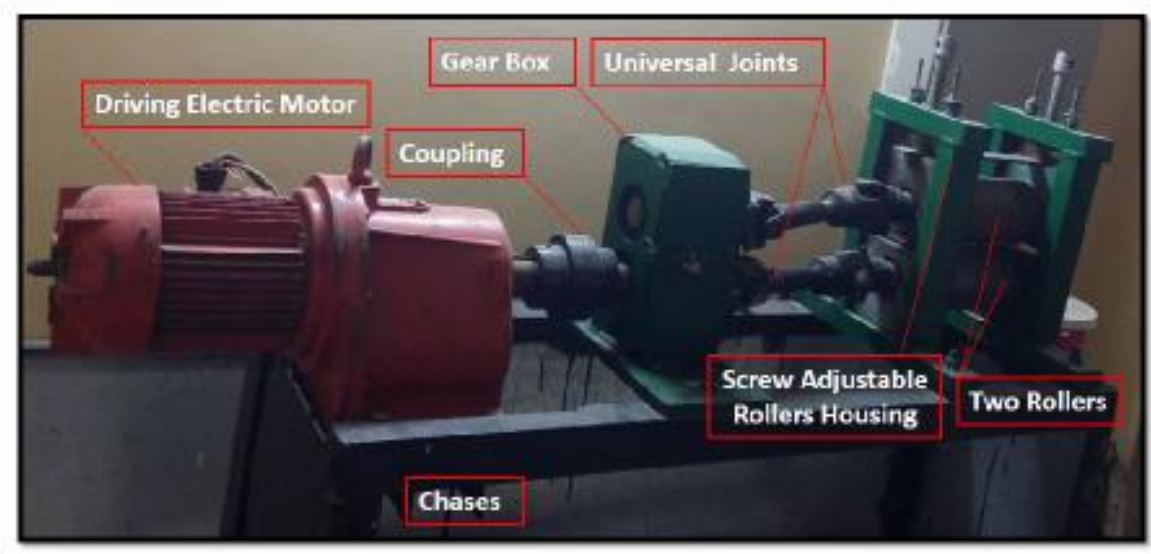

Figure 2. The Rolling Machine Used In The Experimental Work

Flat plates of Aluminum 1100 with initial cross-sectional dimension of 10x20 (mm2) was the investigated material during the rolling experiments to validate the modeling results. The cold rolling process was started after preparing sample and adjusting the gap between two rolls using filler. Power consumption during rolling process was measured with clamp wattmeter. Rolling process was repeated for different drafts by changing the gap between the two rolls and measuring the consumed power for each process. The experiments were conducted under three different roll-material interface conditions; dry rolling, water lubrication, Olive or paraffin oil lubrication. These lubricants are selected for the sake of experiment, however, in industry the lubricants are usually mineral oils, applied either in neat or emulsion form. Lubricants facilitate the reduction of strip by reducing the rolling force required for the deformation, resulting in a lower energy. It is also resulted in high surface quality, resulting in higher value added product. Lubrication also, Reduces roll wear and decreases the needed for frequent roll changes.

\section{RESULTS AND DISCUSSION}

For the flat rolling process, it is recommended to use suitable lubricant to secure maintain good energy conservation by decreasing the roll separating force during the rolling process. It is also expected to have additional protection of the work roll surfaces, control of the coefficient of friction, and control of the resulting surface parameters and cooling. It is worth mentioning that, the coefficient of friction (COF) is generally affected by the reduction ratio "draft", rolling velocity, material yield strength, and surface hardness. As example, COF decreases as the velocity increases. Pure aluminum rolling without lubrication shows higher $\mathrm{COF}$ compared to steel or a harder aluminum alloys rolling.

In the present study, effects of changing COF in the value of rolling separating force and the consumed power was observed as following;

In Figure 3, the relation between measured power and draft for different lubricants are plotted. The general trend of each data group show the effect of the lubricant type on reducing the power consumption. Yet, at larger drafts the effect is less discernible. This could be attributed to the high squeezing forces experienced by the hydrodynamic film under fixed rolling speed, 
which minimizes the incorporation of the lubricant layer at the roll work piece interface. This effect could be alleviated in the industrial setting by adjusting the speed with which the rolls rotate to higher speeds at larger drafts to maintain a comparable lubrication efficiency.

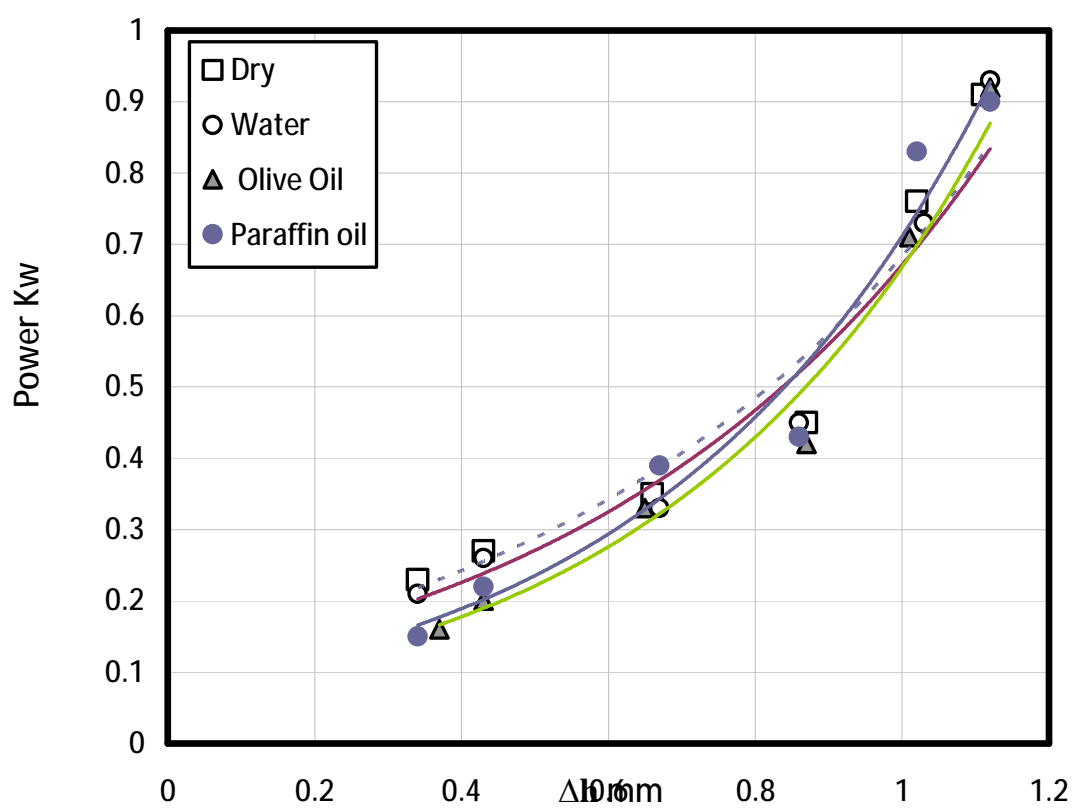

Figure 3. The Relation Between Power And Draft For Aluminum1100, Velocity 0.21m/S Under Dry, Water, Olive Oil And Paraffin Oil Conditions.

Figure 4, shows the power consumption of the investigated rolling process as a function of time under different lubrication. It is worth mentioning that, the draft of the rolled plates was fixed as $0.34 \mathrm{~mm}$ during the different power measurements experiments. According to figure 4 , the cold rolling process of aluminum plate causes higher power consumption for the dry rolling condition, whilst its value shows significant reduction with applying any kind of lubricant either water or oil, but most preferably, paraffin oil. Power was increased gradually when the metal is gripped between rollers and reach relatively steady value when the deformation is in the steady state region. Finally, at the end of rolling process power decreases gradually to reach the idle power.

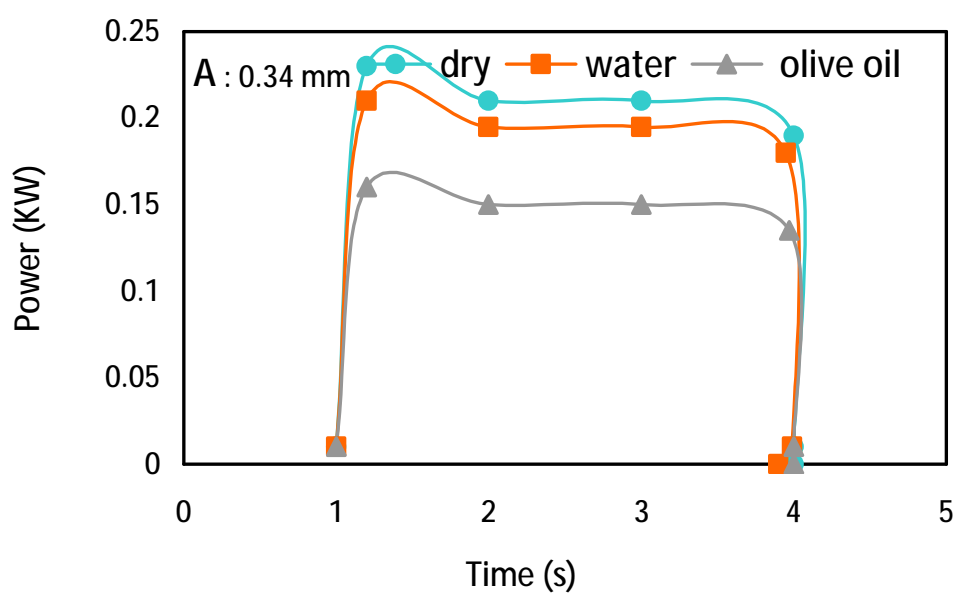

Figure 4. The Relation Between Power And Time Under; Dry, Water, Olive Oil Conditions For Aluminum Plates At Rolling Velocity $0.21 \mathrm{~m} / \mathrm{S}$. 
The total power consumption for each complete rolling cycle are shown by the area under the curve in figure 4 . Interestingly, there is a clear peak of power at the beginning of each rolling process due to the gripping condition of the stock. Unfortunately, the lubricant type at the same speed and the same draft has a small effect on this peak. This could be explained by the friction of the initial gripping condition.

Figure 5 shows the effect of roll diameter on the value of the separated force generated during the cold rolling process as estimated mathematically by applying Ekelund's model for $1 \mathrm{~mm}$ draft of aluminum plates.

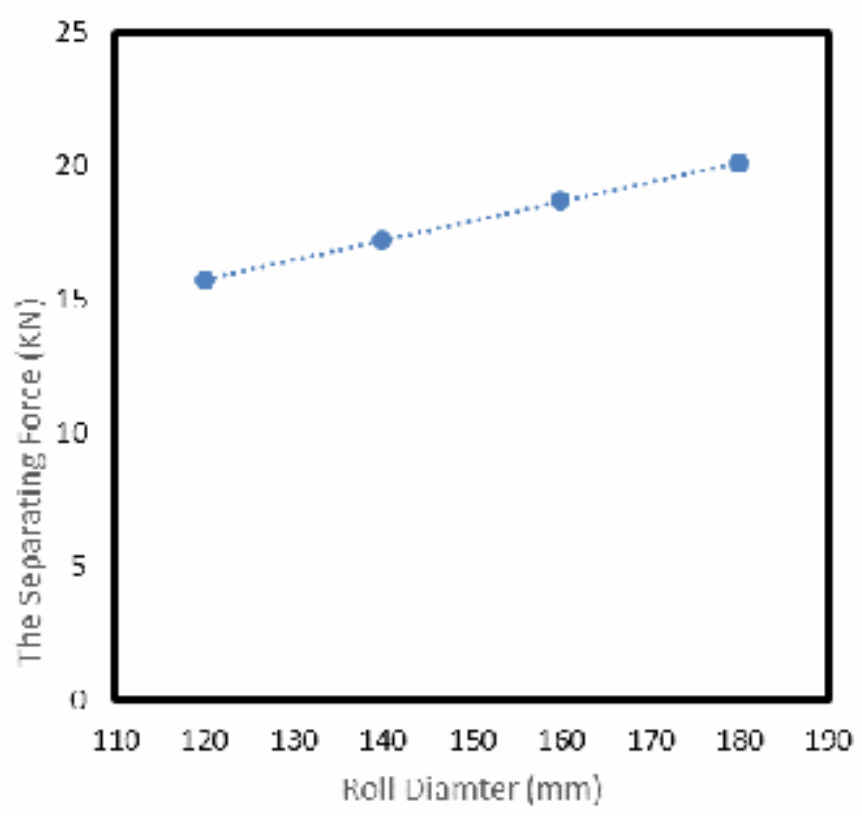

Figure 5. Shows The Relation Between The Separating Force And Different Roll Diameter For Aluminum Plate Cold Rolling.

Generally, with increasing the work roll diameter, both the contact length and the contact area of the roll bite increase, and therefore it raises the value of rolls separating force and the frictional work rate. Subsequently, it leads to a change of the stress state in the roll bite, and higher rolling pressure. Therefore, to reduce the load on the rolling mill and save the energy in the rolling process, it is recommended to reduce the diameter of work roll if it is practicable. When studying the change of draft during the rolling process it is necessary to investigate the value of roll separating force. The rolls separating force is a main parameter during the current investigation study because it governs the process of selecting all rolling mills and motors. The calculation of roll separating force is necessary to ensure that the mill is not overloaded and there is enough power available for the rolling reduction to be accomplished. Figure 6 shows the experimental validation of the roll separating force calculated mathematically by Ekelund, Tselikov, and Seibel models by the calculated force from the power consumed at different drafts. As explained previously and shown here by the experimental and mathematical calculations, the increase in draft during the rolling process lead to a linear increase in rolls separating force, as well as the power consumption. Change in parameters during the rolling process is important because of its effect on rolling setup, geometrical accuracy and mechanical properties of the rolled material. 


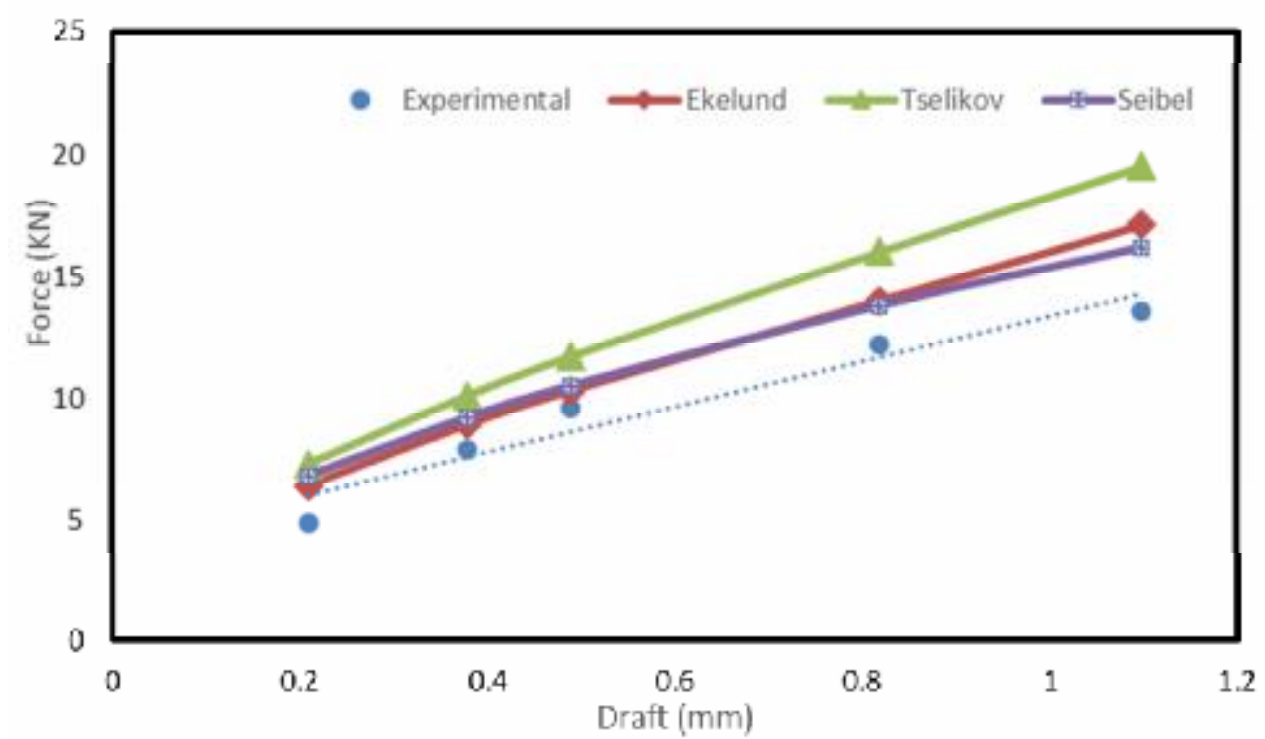

Figure 6. Mathematical Validation Results For Different Mathematical Models Which Relate The Rolls Separating Force To The Draft For Aluminum Plate Cold Rolling.

\section{CONCLUSIONS AND FUTURE WORK}

New exponential setup was successfully built to perform adjustable rolling for aluminum plates. Using this device, some important parameters affecting the cold rolling process of aluminum plates has been investigated, such as power rate, rolls separating force, roll diameter, draft thickness, and lubrication. The effect of draft thickness on rolls separating force and the subsequent power consumption was further investigated using different mathematical models to support the experimental findings and obtain practical validation. Some interesting findings of the current study can be concluded as following;

1- In a strong agreement with the mathematical modelling, the increase in aluminum plate draft during the cold rolling process leads to a linear increase in rolls separating force, as well as the power consumption.

2- With increasing the work roll diameter, both the contact length and the contact area of the roll bite increase, and therefore it raises the value of rolls separating force.

3- It is recommended to use suitable lubricant and minimum rolls diameter as possible, during the flat rolling process of aluminum plates, to secure maintain good energy conservation by decreasing the roll separating force during the rolling process.

4- The cold rolling process of aluminum plate causes higher power consumption for the dry rolling condition, whilst its value shows significant reduction with applying any kind of lubricant and preferably the paraffin oil.

\section{REFERENCES}

1. V. B. Ginzburg and R. Ballas, Flat rolling fundamentals, 1st ed. CRC, 2000.

2. E. G. Thomsen, C. T. Yang, and S. Kobayashi, Mechanics of Plastic Deformation In Metal Processing. McMillan, 1965.

3. Z. Wusatowski, fundamentals of rolling. Pergamon press,New York, 2012.

4. Dawson, Paul R. "On modeling of mechanical property changes during flat rolling of aluminum." International journal of solids and structures 23.7, 947-968.1987.

5. Çalışkan, Emel, et al. "Characteristics of Surface Properties of Aluminum Flat Products Related with Different Annealing Temperature and Cleaning Properties." Light Metals 2019. Springer, Cham, 323-329, 2019.

6. D. Jortner, J. F. Osterle, and C. F. Zorowski, "An analysis of cold strip rolling," Int. J. Mech. Sci., vol. 2, pp. 179-194, 1960.

7. J. G. Lenard, Primer on Flat Rolling, 2nd ed. Elsevier, 2014. 
8. F. A. R. Al-Salehi, T. C. Firbank, and P. R. Lancaster, "An experimental determination of the roll pressure distributions in cold rolling," Int. J. Mech. Sci., vol. 15, no. 9, pp. 693-710, 1973.

9. E. Orowan, "The Calculation of Roll Pressure in Hot and Cold Flat Rolling," Proc. Inst. Mech. Eng., vol. 150, pp. 140-167, 1943.

10. E. Orowan, "Communications on The Calculation of Roll Pressure in Hot and Cold Flat Rolling," Proc. Inst. Mech. Eng., vol. 150, pp. 314-324, 1943.

11. D. R. Bland and R. B. Sims, "A Note on the Theory of Rolling with Tensions," pp. 371-374, 1952.

12. J. M. Alexander, "O n the Theory of Rolling," Proc. R. Soc. A Math. Phys. Eng. Sci., vol. 329, no. 1579, pp. 493-496, 1972.

13. J. M. Alexander, "Corrigenda: On the Theory of Rolling," Proc. R. Soc. A Math. Phys. Eng. Sci., vol. 329, no. 1579, pp. 493-496, 1972.

14. K. Devarajan, K. P. Marimuthu, and A. Ramesh, "FEM Analysis of Effect of Rolling Parameters on Cold Rolling Process," vol. 2, no. 1, pp. 35-40, 2012.

15. H. S. Valberg, Applied Metal Forming: Including Fem Analysis. Cambridge University Press, 2010.

16. Pietrzyk, M., \& Lenard, J. G. Thermal-mechanical modelling of the flat rolling process. Springer Science \& Business Media, 2012.

17. Alexa, V., S. Raţiu, and I. Kiss. "Metal rolling-Asymmetrical rolling process." IOP Conference Series: Materials Science and Engineering. Vol. 106. No. 1. IOP Publishing, 2016. 